\title{
Effect of Tempers on Electrochemical Corrosion Behavior of 7150 Aluminum Alloy Plate in Various Corrosive Media
}

\author{
Qingqing Sun ${ }^{1,2,3}$, Jiugang $\mathrm{Hu}^{1}$, Jie Li ${ }^{1, *}$, Kanghua Chen ${ }^{2}$, Pengxuan Dong ${ }^{2}$, Xingzhi Liao ${ }^{2}$, \\ Yang Yang ${ }^{3}$ \\ ${ }^{1}$ School of Chemistry and Chemical Engineering, Central South University, Changsha 410083, Hunan, \\ China \\ ${ }^{2}$ State Key Laboratory of Powder Metallurgy, Central South University, Changsha 410083, Hunan, \\ China \\ ${ }^{3}$ School of Chemical Engineering, Purdue University, West Lafayette 47907, IN, USA \\ *E-mail: lijieliu@csu.edu.cn
}

doi: $10.20964 / 2017.06 .63$

Received: 31 May 2016 / Accepted: 13 April 2017 / Published: 12 May 2017

The effect of various tempers (peak ageing T6, RRA T77, two-step ageing T76, and a novel three-step ageing T76 + T6) on electrochemical corrosion of $7150 \mathrm{Al}$ alloy under three corrosive solutions has been investigated. Electrochemical results and corrosion morphologies show that the resistance to pitting corrosion, inter-granular corrosion (IGC) and exfoliation corrosion of alloys is in the following decreasing order: T76 + T6 > T76 > T77 > T6. As indicated by TEM, the corrosion behavior of each temper might depend on the size and spacing of grain boundary particles of alloys. Excellent consistence between electrochemical parameter and stress cracking corrosion resistance was observed. In addition, the pit transition potential and potential differences as criteria to assess $\mathrm{Al}$ alloy corrosion behavior were also discussed.

Keywords: $7150 \mathrm{Al}$ alloy; Temper; Cyclic polarization; Potential; TEM

\section{FULL TEXT}

(C) 2017 The Authors. Published by ESG (www.electrochemsci.org). This article is an open access article distributed under the terms and conditions of the Creative Commons Attribution license (http://creativecommons.org/licenses/by/4.0/). 